\title{
Role of Toll-like receptor 2 in mediating the production of cytokines and human beta-defensins in oral mucosal epithelial cell response to Leptospiral infection
}

\author{
Naharuthai Inthasin, ${ }^{1}$ Patimaporn Wongprompitak, ${ }^{1}$ Chawikan Boonwong, ${ }^{2}$ Pattama Ekpo ${ }^{1}$
}

\begin{abstract}
Background: Pathogenic Leptospira spp. is the causative agent of leptospirosis. Oral mucosal cavity is one of portal entry for this bacterium. Oral mucosal epithelium provides a physical barrier and secretes cytokines, chemokines and antimicrobial peptides (AMPs) in response to microbial infection. Human $\beta$-defensins (hBDs); hBD1, hBD2, and hBD3 are predominantly AMPs expressed in the oral cavity. Toll-like receptors (TLRs) have been reported in hBD regulation. TLR2 recognizes leptospiral lipopolysaccharide, and plays a key role in the early control of leptospirosis.
\end{abstract}

Objective: The aim of this study is to investigate the role of TLR2 in mediating the production of cytokines and hBDs in oral mucosal epithelial cell response to leptospiral infection.

Methods: Cultivated oral mucosal epithelial cells were prepared, characterized, and compared with oral mucosal tissues. The TLR1-10 and hBD mRNA expressions were examined. Pro-inflammatory cytokine and hBD1-3 expressions in response to leptospires were determined by quantitative (q) RT-PCR.

Results: The cultivated oral epithelium expressed TLR2 and $h B D 1-3$. The induction of $I L-1 \beta, I L-8, T N F-\alpha$, and $h B D 2$ were increased in response to Leptospira via TLR2 recognition.

Conclusion: The characteristics of primary epithelial cells and tissue were similar in terms of TLR expression. All primary epithelial cells expressed TLR2 and hBD1-3. We used primary epithelial cells to study response to $L$. interrogans. Our results yielded the first evidence that human TLR2 regulates $h B D 2$ expression in oral mucosa epithelial responded to L. interrogans. Expression of $h B D 2$ may act to neutralize the virulence or prevent the invasion of L. interrogans at the portal of entry.

Key word: TLR2, leptospirosis, oral mucosal epithelium, human beta-defensins, Leptospira

\footnotetext{
From:

Department of Immunology, Faculty of Medicine Siriraj Hospital, Mahidol University, Bangkok 10700, Thailand

Research Division, Faculty of Medicine Siriraj Hospital, Mahidol University, Bangkok 10700, Thailand
}

\author{
Corresponding author: \\ Pattama Ekpo \\ Department of Immunology, Faculty of Medicine Siriraj Hospital, Mahi- \\ dol University, Bangkok 10700, Thailand \\ Email: pattama.ekp@mahidol.ac.th
}

\section{Introduction}

Pathogenic Leptospira spp. is the causative agent of leptospirosis. ${ }^{1}$ Portals of entry include cuts and abrasions, and mucous membranes, such as the conjunctival, genital, and oral mucous membranes. Disease transmission is usually associated with water, including flood and drinking or swimming in contaminated water. It was reported that swallowing of water while swimming increases the risk of developing leptospirosis. ${ }^{2}$ Leptospires agglutinate when mixed with human or hamster saliva. ${ }^{3-5}$ A high dose of leptospires is required for oral mucosal infection in hamster. ${ }^{5}$ These studies suggest that oral mucosal immunity plays an important role in the defense against leptospiral infection.

Human $\beta$-defensins (hBDs) are cationic antimicrobial peptides (AMPs) that are secreted from epithelium and salivary glands to maintain balance between commensal structures and to prevent or act against infection. ${ }^{6-8}$ The mechanism of hBDs is to induce bacterial lysis by targeting negatively charged molecules in the cell wall of bacteria, such as lipopolysaccharide 
(LPS) and lipoteichoic acid. In addition to bactericidal activity, hBDs play a role in leukocyte recruitment to initiate adaptive immune response. The oral cavity expresses hBD1, hBD2, and hBD3. hBD1 is constitutively expressed, whereas hBD2 and $\mathrm{hBD} 3$ are induced by microbial infection or inflammatory cytokines, such as IL- $1 \beta$, TNF- $\alpha$, and IFN- $\gamma \cdot{ }^{6,8-10}$

Toll-like receptors (TLRs) are pattern recognition receptors (PRRs) in the innate immune system that are specifically activated by their cognate ligands. The activation of TLRs initiates host inflammatory response to defend against infection. TLR2 is a major PRR in the oral cavity that induces the upregulation of hBDs. Several periodontal bacteria, including Fusobacterium nucleatum, Treponema denticola, and Porphyromonas gingivalis, induce TLR2-mediated hBD2 and/or hBD3 expression. ${ }^{8,10,11}$ In addition to TLR2, other TLRs, including TLR3, TLR4, TLR5, and TLR9, have been reported to be associated with hBD regulation. ${ }^{10-12}$

TLR2 plays a significant role in human leptospirosis. ${ }^{13-15}$ Due to the presence of leptospiral LPS, a previous study reported that leptospires are more susceptible to AMPs than are other spirochete bacterium. ${ }^{16}$ Leptospiral LPS is recognized by human TLR2, whereas the LPS of Gram-negative bacteria are recognized by human TLR4. ${ }^{17}$ Based on our review of the literature, the role of TLR as a mediator of hBD production in host response to leptospires has not been investigated. Accordingly, the aim of this study was to investigate the role of TLR2 in mediating the production of cytokines and hBDs in oral mucosal epithelium response to leptospiral infection. We found that the cultivated oral mucosal epithelium responded to Leptospira infection by increase the levels of pro-inflammatory cytokine; $I L-1 \beta, I L-8, T N F-\alpha$, and $h B D 2$ expressions. The $h B D 2$ expression, a mechanism against and neutralize bacterial invasion at the route of entry, was induced via TLR2 recognition.

\section{Methods}

\section{Bacterial culture and preparation}

L. interrogans serovar Autumnalis was isolated from clinical specimens obtained from patients admitted to Siriraj Hospital, which is located in Bangkok, Thailand. Siriraj Hospital is Thailand's largest university-based national tertiary referral center. The protocol for this study was approved by the Siriraj Institutional Review Board, Faculty of Medicine Siriraj Hospital, Mahidol University, Bangkok, Thailand (IEC no 639/ 2551(EC2)). The bacteria were cultured in Ellinghausen -McCullough-Johnson-Harris (EMJH) medium supplemented with leptospiral enrichment (HiMedia Laboratories, Mumbai, India) at $30^{\circ} \mathrm{C}$. On the day of infection, the bacteria were washed by centrifugation at $10,000-\mathrm{x} g$ for 10 minutes in sterile PBS. After being washed two times, the pellet was resuspended in cell culture medium and infected into cultivated oral mucosal epithelium. The cytokine expressions of the infected cell were analyzed by quantitative real-time polymerase chain reaction (qRT-PCR).

\section{Oral mucosal epithelium cultivation and isolation}

Oral tissues were harvested from 8 healthy adults ( 5 females and 3 males; age range: $22-73$ years) after obtaining written informed consent and performing a pre-surgical evaluation. Oral hygiene was optimized with preoperative $1 \%$ Betadine ${ }^{\circledast}$ mouthwash for 3 days prior to biopsy. On the day of operation, an oral mucosal biopsy of $5 \mathrm{~mm}$ x $5 \mathrm{~mm}$ was harvested from the buccal surface of the lower lip under local anesthesia.

Oral mucosal tissue specimens were digested using $2 \mathrm{IU} /$ $\mathrm{ml}$ of Dispase II neutral protease (Thermo Fisher Scientific, Waltham, MA, USA) at $4^{\circ} \mathrm{C}$ overnight after being washed three times in Dulbecco's phosphate buffered saline (DPBS) (Thermo Fisher Scientific, Waltham, MA, USA ). After incubation, the epithelial sheet was separated, and washed three times, cut into small pieces, and separated into single cells by trypsin digestion method. Cells were plated at $10^{4}$ cells $/ \mathrm{cm}^{2}$ in a cell culture dish containing keratinocyte growth medium (KGM) (Lonza, Basel, Switzerland) and incubated for two to three weeks in a humidified incubator at $37^{\circ} \mathrm{C}$ with $5 \% \mathrm{CO}_{2}$. The medium was changed every other day. The cells of early passage were preserved in liquid nitrogen until use.

\section{RNA extraction and total RNA quantification}

RNA from oral mucosal epithelial sheet, cultivated oral mucosal epithelium, and infected cells was extracted using RNeasy Mini Kit (Qiagen, Hilden, Germany) according to manufacturer's protocol. RNA concentration was determined by spectrophotometric measurement at $260 \mathrm{~nm}$ (Nanodrop, Thermo Scientific, Wilmington, DE, USA). $\mathrm{A}_{260} / \mathrm{A}_{280}$ ratio was calculated to determine the purity of RNA. The allowable range of RNA purity was 1.9-2.1.

\section{Reverse transcription polymerase chain reaction (RT-PCR)}

Total RNA was extracted and subsequently reverse-transcribed using the Superscript ${ }^{\mathrm{TM}}$ III First Strand Synthesis System (Life Technologies, Carlsbad, CA, USA). The cDNA preparations were stored at $-20^{\circ} \mathrm{C}$ until PCR amplification. RT-PCR was used to determine the expression of TLR1-10 and $h B D 1-3$ genes of oral epithelial tissue and cultivated cells. The optical density of PCR products was analyzed by agarose gel electrophoresis using ImageJ image analysis software. GAPDH was used as a housekeeping gene and as an internal control for normalization. Nucleotide sequences of primers used for PCR analysis are shown in Table $\mathbf{1 .}$

\section{Analysis of MRNA expression by $q R T-P C R$}

The mRNA expression of Leptospira-infected oral mucosal epithelium was quantified at 4 hours after infection by qRTPCR. For blocking of TLR2 activity, cells were pre-incubated with anti-human TLR2 (InvivoGen, San Diego, CA, USA) before infection. The culture media of infected cells was removed before adding the lysis buffer. Total RNA was extracted and the fifty to one-hundred $\mathrm{ng} / \mathrm{ml}$ of RNA was reverse-transcribed to cDNA.

The PCR mixture consisted of iTaq SYBR Green Master Mix (Bio-Rad Laboratories, Hercules, CA, USA), $0.5 \mu \mathrm{M}$ of forward and reverse primers, and $5 \mu \mathrm{l}$ of $1 / 10$ diluted cDNA. PCR was performed using the following conditions: enzyme activation at $95^{\circ} \mathrm{C}$ for $10 \mathrm{~min}$ and 40 cycles of denaturation at $95^{\circ} \mathrm{C}$ for $10 \mathrm{sec}$; annealing at $59^{\circ} \mathrm{C}$ for $15 \mathrm{sec}$; and, extension at $72^{\circ} \mathrm{C}$ for $5 \mathrm{sec}$ with fluorescence detection. The expressions of pro-inflammatory cytokine, including $h B D 1-3, I L-1 \beta, I L-8$, and TNF- $\alpha$ were determined. The quantification cycle $(\mathrm{Cq})$ of target mRNA was 
Table 1. Primer sequences used for PCR analysis, their corresponding melting temperatures (Tm) and sizes of PCR products (base pairs).

\begin{tabular}{|c|c|c|c|c|}
\hline Gene & Sequence $\left(5^{\prime} \rightarrow 3^{\prime}\right)$ & $\operatorname{Tm}$ & Size & Accession no. \\
\hline TLR1_F & CAGTGTCTGGTACACGCATGGT & 59 & 105 & NM_003263 \\
\hline TLR1_R & TTTCAAAAACCGTGTCTGTTAAGAGA & 55 & & \\
\hline TLR2_F & GTACCTGTGGGGCTCATTGT & 57 & 178 & NM_003264 \\
\hline TLR2_R & TACCATTGCGGTCACAAGAC & 55 & & \\
\hline TLR3_F & CCTCCAGCACAATGAGCTATC & 55 & 197 & NM_003265 \\
\hline TLR3_R & CCAGCTGAACCTGAGTTCCT & 57 & & \\
\hline TLR4_F & AACCAAGAACCTGGACCTGA & 56 & 185 & NM_138554 \\
\hline TLR4_R & AACTCTGGATGGGGTTTCCT & 56 & & \\
\hline TLR5_F & СССТCTGCCССТAGAATAAGA & 55 & 150 & NM_003268 \\
\hline TLR5_R & CTATTCGGCCATCAAAGGAG & 53 & & \\
\hline TLR6_F & CATGTTCCAAAAGACCTACCGC & 56 & 234 & NM_006068 \\
\hline TLR6_R & ACTCACAATAGGATGGCAGGATA & 55 & & \\
\hline TLR7_F & TGTTTCCAATGTGGACACTGAA & 55 & 195 & NM_016562 \\
\hline TLR7_R & TGTTCGTGGGAATACCTTCCAG & 56 & & \\
\hline TLR8_F & TTTCAAGGGCTGCAAAATCTCA & 55 & 163 & NM_138636 \\
\hline TLR8_R & ACTGGTTGTCTTCAAGCAGTAAC & 55 & & \\
\hline TLR9_F & CССАССТGTCACTCAAGTACA & 56 & 242 & NM_017442 \\
\hline TLR9_R & GTGGCTGAAGGTATCGGGATG & 58 & & \\
\hline TLR10_F & GGCACAGGGTTAGGAAAACA & 55 & 302 & NM_001195108 \\
\hline TLR10_R & GAGATTGTGGTGGGCAAAGT & 56 & & \\
\hline hBD1_F & CTGCTGTTTACTCTCTGCTTACTTTT & 62 & 107 & NM_005218 \\
\hline hBD1_R & CCTCCACTGCTGACGCA & 50 & & \\
\hline hBD2_F & GATCCTGTTACCTGCCTTAAGAGT & 62 & 83 & NM_001205266 \\
\hline hBD2_R & CCACAGGTGCCAATTTGTTTATACC & 60 & & \\
\hline hBD3_F & GTCATGGAGGAATCATAAACACATTACAG & 56 & 100 & NM_018661 \\
\hline hBD3_R & CCGATCTGTTCCTCCTTTGGA & 62 & & \\
\hline IL-8_F & GCCAACACAGAAATTATTGTAAAGCTT & 56 & 112 & NM_000584 \\
\hline IL-8_R & AATTCTCAGCCСТCTTCAAAAACTT & 55 & & \\
\hline GAPDH_F & CCTGTTCGACAGTCAGCCG & 58 & 101 & NM_002046 \\
\hline GAPDH_R & CGACCAAATCCGTTGACTCC & 56 & & \\
\hline
\end{tabular}

normalized with the GAPDH gene and an unstimulated cell using the $\triangle \Delta \mathrm{Cq}$ method.

\section{Results}

Characterization of TLR and hBD expressions in oral mucosal epithelium

To demonstrate that cultivated oral mucosal epithelium can be used as a model to study oral innate immunity, we compared TLR1-10 and $h B D 1-3$ mRNA expressions of oral epithelium cell sheets with cultivated oral mucosal epithelium. We found that cultivated oral epithelium expressed TLRs similar to those expressed by the oral epithelium cell sheet (Table 2, Figure 1). Most patients expressed all of TLR1-10. However, differences in TLR expression were observed in some patients. One patient did not express both TLR1 and TLR2, one patient did not express TLR8, and two of eight patients did not express TLR7 on the oral epithelium sheet. After cultivation, one patient did not express TLR1, TLR4, or TLR8. Notably, TLR2 was expressed in all of the cultivated cells. Regarding TLR expression, we found that all of $h B D 1-3$ were detectable by RTPCR in all tissues and in all cultivated cells (Table 2, Figure 1). Therefore, the oral mucosal epithelium that was cultivated in our laboratory can be used as a model for studying the role of TLR2 as a mediator of induction of hBDs by L. interrogans in oral mucosal epithelial cells.

Induction of hBDs and pro-inflammatory cytokines in response to Leptospira interrogans

To determine whether cultivated oral mucosal epithelium responded to leptospiral infection, $2 \times 10^{4}$ cells was plated in a 96-well plate for 2 days before infection with 100 multiplicities of infection (MOI) of L. interrogans. After infection for duration of 4 hours, the infected cells were collected and evaluated for cytokine expression by qRT-PCR. We found that $L$. interrogans induced the up regulation of pro-inflammatory cytokine 
Table 2. Eight human oral mucosal epithelial sheets $(S)$ and their cultivated oral mucosal epithelium (C) expressed TLR- and $h B D$-specific mRNAs

\begin{tabular}{|c|c|c|c|c|c|c|c|c|c|c|c|c|c|c|c|c|c|c|c|c|c|c|c|c|c|c|}
\hline \multirow{2}{*}{$\begin{array}{l}\text { Sample } \\
\text { Number }\end{array}$} & \multicolumn{2}{|c|}{$\begin{array}{c}\text { TLR } \\
1\end{array}$} & \multicolumn{2}{|c|}{$\begin{array}{c}\text { TLR } \\
2\end{array}$} & \multicolumn{2}{|c|}{$\begin{array}{c}\text { TLR } \\
3\end{array}$} & \multicolumn{2}{|c|}{$\begin{array}{c}\text { TLR } \\
\mathbf{4}\end{array}$} & \multicolumn{2}{|c|}{$\begin{array}{c}\text { TLR } \\
5\end{array}$} & \multicolumn{2}{|c|}{$\begin{array}{c}\text { TLR } \\
6\end{array}$} & \multicolumn{2}{|c|}{$\begin{array}{c}\text { TLR } \\
7\end{array}$} & \multicolumn{2}{|c|}{$\begin{array}{c}\text { TLR } \\
8\end{array}$} & \multicolumn{2}{|c|}{$\begin{array}{c}\text { TLR } \\
9\end{array}$} & \multicolumn{2}{|c|}{$\begin{array}{c}\text { TLR } \\
10\end{array}$} & \multicolumn{2}{|c|}{$\begin{array}{c}\text { hBD } \\
1\end{array}$} & \multicolumn{2}{|c|}{$\begin{array}{c}\text { hBD } \\
2\end{array}$} & \multicolumn{2}{|c|}{$\begin{array}{c}\text { hBD } \\
3\end{array}$} \\
\hline & $\mathbf{S}$ & C & $S$ & C & $\mathbf{S}$ & C & $\mathbf{S}$ & C & $\mathbf{S}$ & C & $S$ & C & $S$ & C & $\mathbf{S}$ & C & $\mathbf{S}$ & C & $\mathbf{S}$ & C & $\mathbf{S}$ & C & $\mathbf{S}$ & C & S & C \\
\hline 1 & + & - & + & + & + & + & + & - & + & + & + & + & + & + & + & - & + & + & + & + & + & + & + & + & + & + \\
\hline 2 & + & + & + & + & + & + & + & + & + & + & + & + & - & + & - & + & + & + & + & + & + & + & + & + & + & + \\
\hline 3 & + & + & + & + & + & + & + & + & + & + & + & + & - & + & + & + & + & + & + & + & + & + & + & + & + & + \\
\hline 4 & + & + & + & + & + & + & + & + & + & + & + & + & + & + & + & + & + & + & + & + & + & + & + & + & + & + \\
\hline 5 & - & + & - & + & + & + & + & + & + & + & + & + & + & + & + & + & + & + & + & + & + & + & + & + & + & + \\
\hline 6 & + & + & + & + & + & + & + & + & + & + & + & + & + & + & + & + & + & + & + & + & + & + & + & + & + & + \\
\hline 7 & + & + & + & + & + & + & + & + & + & + & + & + & + & + & + & + & + & + & + & + & + & + & + & + & + & + \\
\hline 8 & + & + & + & + & + & + & + & + & + & + & + & + & + & + & + & + & + & + & + & + & + & + & + & + & + & + \\
\hline
\end{tabular}

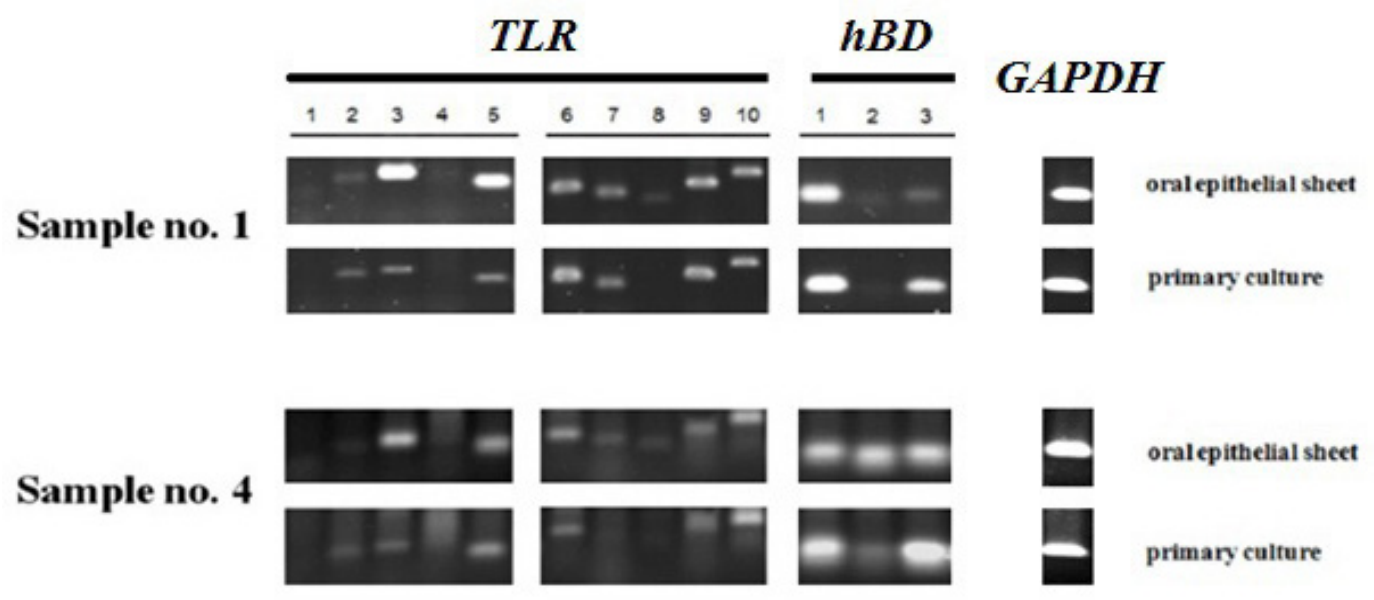

Figure 1. Expressions of TLR1-10 and $h B D 1-3$ genes determined by RT-PCR in human oral mucosal epithelial sheets, and in corresponding cultured cells of 2 representative donors. The GAPDH gene was observed between samples as a loading control. The numbers of 1-10 and 1-3 represent TLR1-10 and $h B D 1-3$, respectively.

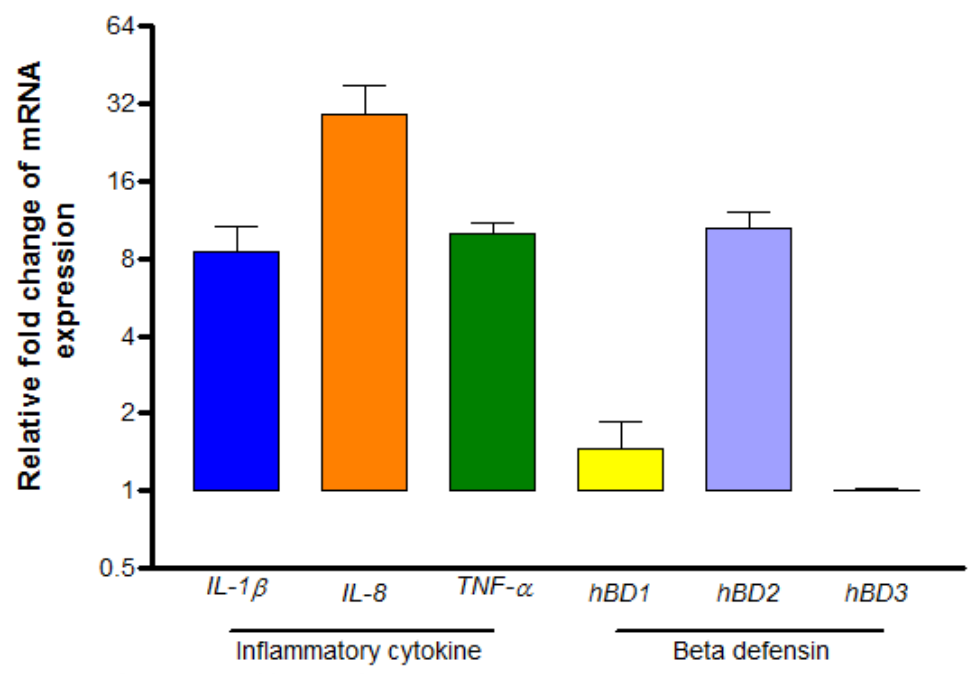

Figure 2. Pro-inflammatory cytokine and $h B D$ expressions in cultivated oral mucosal epithelium response to 100 MOI Leptospira. The graph shows mean \pm standard error of the mean (SEM) of one representative experiment which was performed in duplicate. 


\section{Cytokine expression}

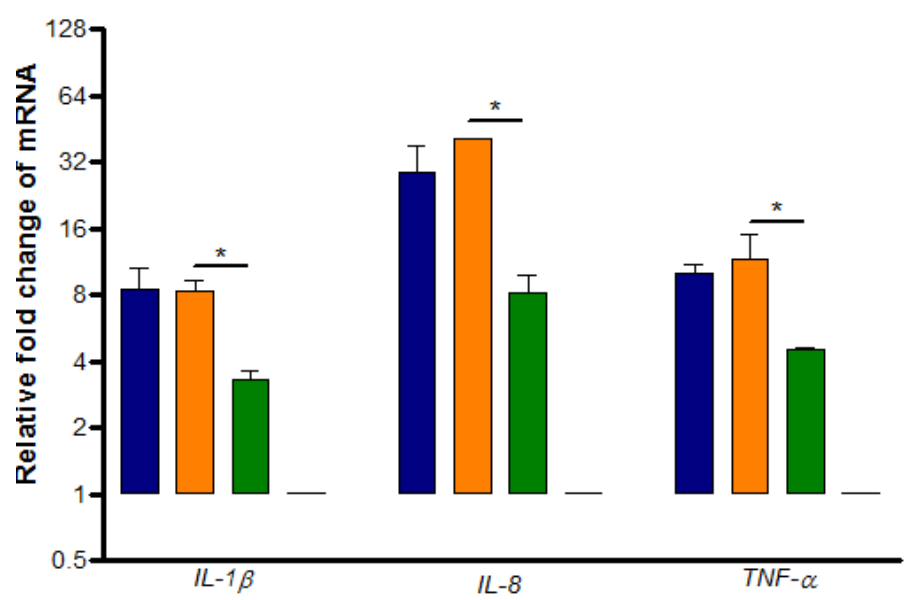

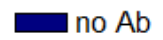

$\square$ Isotype Ab $\square$ anti-hTLR2

Human $\beta$-defensin 2

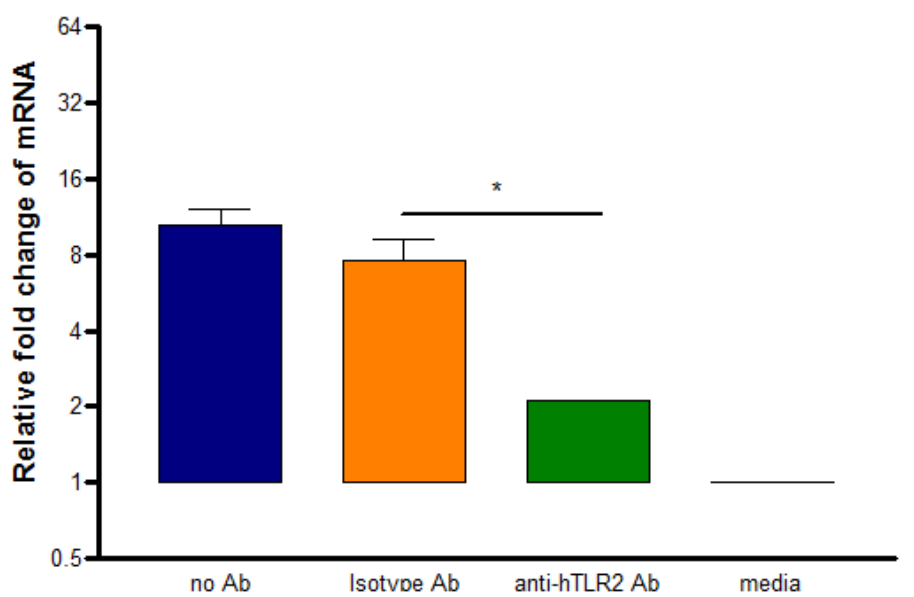

Figure 3. The effect of anti-hTLR2 neutralizing Ab on $L$. interrogans stimulated pro-inflammatory cytokine and $h B D 2$ expressions. Cultivated oral mucosal epithelium were pre-incubated with or without $10 \mu \mathrm{g} / \mathrm{ml}$ anti-hTLR2 neutralizing or isotype control $\mathrm{Ab}$ for 1 hour before infection, and were stimulated with L. interrogans at MOI 100. The graph shows mean \pm standard error of the mean (SEM) of one representative experiment which was performed in duplicate. Statistical difference between anti-hTLR2 and isotype control $\mathrm{Ab}$ was analyzed by paired-t-test, * statistical difference at $p$-value $<0.05$.

$I L-1 \beta, I L-8$, and TNF- $\alpha$ (Figure 1). Expression of $h B D 1-3$ can be observed in both non-inflamed tissue and in cultured cells. However, only the expression of $h B D 2$ was increased after leptospiral infection (Figure 2). This result indicated that cultivated oral mucosal epithelium has the ability to respond to leptospiral infection by increasing the expression of pro -inflammatory cytokine and $h B D 2$.

\section{Role of TLR2 in oral mucosal response to leptospiral infection}

To study the effect of human TLR2 on oral mucosal epithelium in response to leptospiral infection, we pre-incubated the cells with anti-hTLR2 Ab for 1 hour before infection. The expression of pro-inflammatory cytokine $I L-1 \beta, I L-8, T N F-\alpha$, and $h B D 2$ were significantly reduced in the presence of anti -hTLR2 Ab (Figure 3). From this result, we can conclude that TLR2 was the major receptor for induction of pro-inflammatory cytokine and $h B D 2$ expressions in oral mucosal epithelium response to leptospiral infection.

\section{Discussion}

The first evidence that $L$. interrogans induces the expression of $h B D 2$ at the route of infection is reported herein. Increases in $h B D 2$, as well as $I L-1 \beta, T N F-\alpha$, and $I L-8$, in oral mucosal epithelium were dependent on TLR2 activation. TLR2 is recognized as an important TLR in human leptospirosis that initiates host inflammatory response. ${ }^{13-15}$ However; the role of TLR2 in regulated hBD2 expression has never been reported. Therefore, this new finding adds to the existing body of knowledge about host innate immune response to L. interrogans at the site of infection.

Oral mucosal epithelium is a component of the innate immune system that plays a role as both a physical and chemical barrier in host defense. The secretion of hBD is one mechanism that helps to maintain balance in the oral cavity, and that helps to prevent the invasion of several different microbes. TLR, especially TLR2, is the most characteristic PRR that regulates hBD expression in the innate immune system..$^{8,11,12,18}$ TLR 2 has a crucial role in mediating host inflammatory response in human leptospirosis.

First, we characterized TLR expressions in cultivated oral mucosal epithelium. We found that most cultivated oral mucosal epithelium had TLR and $h B D$ mRNA expressions similar to those identified on the fresh isolated oral mucosal sheet. All donors expressed TLR2 and had detectable levels of $h B D 1-3$ mRNA expression. This finding confirmed that the culture condition did not interfere with TLR expression, and that cultivated oral mucosal epithelium can be used as a model for studying innate immunity to L. interrogans.

Differences in constitutively expressed hBD1, hBD2 and hBD3 are induced by microbial or inflammatory stimuli. ${ }^{8}$ Non-inflamed tissue and unstimulated cultured epithelium expressed a low amount of $h B D 1-3$ mRNA expression. However, $h B D 3$ mRNA expression increased after cultivation. This expression may have been caused by the culture condition, which contained epidermal growth factor, which has been reported to induce the expression of $h B D 3 .{ }^{19}$ However, $h B D 3$ did not increase after leptospiral infection. The up regulation of $h B D 2$ in response to L. interrogans may be due to direct stimulation by $L$. interrogans and/or the indirect effect of pro-inflammatory cytokine IL- $1 \beta$ and TNF- $\alpha$. Leptospiral LPS has been reported to be recognized by human TLR2. ${ }^{13,17}$ Under the regulation of TLR, IL- 8 is the key cytokine in activated epithelium. The induction of $h B D 2$ and $I L-8$ by $L$. interrogans was mostly dependent upon TLR2 activation. The anti-hTLR2 neutralizing $\mathrm{Ab}$ blockade reduced the expression of $h B D 2$ by more than $70 \%$ when compared with the expression observed when no blockade was introduced. This finding may suggest that the expression of $h B D 2$ and $I L-8$ were mostly induced by direct interaction between hTLR2 and leptospires. 
In addition to the direct effect of the bacteria, the production of $I L-1 \beta$ and TNF- $\alpha$ in host response to L. interrogans enhanced $h B D 2$ expression. The reduction of these pro-inflammatory cytokine in the presence of anti-hTLR2 Ab could affect the expression of $h B D 2$. Therefore, direct $L$. interrogans induction and host inflammation together synergistically promoted $h B D 2$ expression in oral mucosal response to L. interrogans.

In the present study, we demonstrated that the activation of hTLR2 in host response to L. interrogans not only promoted inflammation, but that it also induced the protective response of AMPs. Increased $h B D 2$ mRNA in response to L. interrogans might enhance host defense against the infection. The secretion of the cationic hBD2 peptide targets the negatively charged cell wall of bacteria. This mechanism may explain why infection via the oral cavity requires a high concentration of leptospiral infection. ${ }^{5}$ The epithelial lining of the oral mucosa provides not only a physical barrier, but it also secretes $\mathrm{hBD}$ to neutralize the infection. In addition to this antibacterial activity, hBD promotes the recruitment of neutrophils to clear the microbes. The anti-inflammatory effect of hBD also reduces host ation, which causes pathology of leptospirosis.

In conclusion, our study provides the first evidence that the initiation of pro-inflammatory cytokine and $h B D 2$ were responsible to leptospiral mediated hTLR2 activation in oral innate immunity. The mechanism by which hBD2 affects $L$. interrogans, and host response at the other portals of entry will be investigated in future studies. The induction of AMPs may produce a protective effect that both prevents leptospiral invasion and that improves or initiates a systemic immune response that protects against leptospirosis. A recent study reported a fatal case of leptospirosis that expressed a higher level of inflammatory cytokine, but a lower level of AMPs than a comparative survival case. ${ }^{20}$ The anti-inflammatory effect of AMPs may prevent excessive host inflammation and protect against fatal leptospirosis.

\section{Acknowledgements}

The authors gratefully acknowledge Dr.Panitee Luemsamran, Department of Opthalmology, Faculty of Medicine Siriraj Hospital, Mahidol University for kindly obtain the oral mucosal epithelial sheet.

\section{Conflict of interest declaration}

The authors hereby declare no personal or professional conflicts of interest regarding

\section{Funding disclosure}

This study was funded by a grant from the Faculty of Medicine Siraraj Hospital, Mahidol University.

\section{References}

1. Bharti AR, Nally JE, Ricaldi JN, Matthias MA, Diaz MM, Lovett MA, et al. Leptospirosis: a zoonotic disease of global importance. Lancet Infect Dis. 2003;3:757-71.

2. Wynwood SJ, Graham GC, Weier SL, Collet TA, McKay DB, Craig SB. Leptospirosis from water sources. Pathog Glob Health. 2014;108:334-8.

3. Stern EJ, Galloway R, Shadomy SV, Wannemuehler K, Atrubin D, Blackmore C, et al. Outbreak of Leptospirosis among Adventure Race Participants in Florida, 2005. Clin Infect Dis. 2010;50:843-9.

4. Lingappa J, Kuffner T, Tappero J, Whitworth W, Mize A, Kaiser R, et al. HLA-DQ6 and ingestion of contaminated water: possible gene -environment interaction in an outbreak of Leptospirosis. Genes Immun. 2004;5:197-202.

5. Asoh T, Saito M, Villanueva SYAM, Kanemaru T, Gloriani N, Yoshida S-i. Natural defense by saliva and mucosa against oral infection by Leptospira. Can J Microbiol. 2014;60:383-9.

6. Dunsche A, Açil Y, Dommisch H, Siebert R, Schröder JM, Jepsen S. The novel human beta-defensin-3 is widely expressed in oral tissues. Eur J Oral Sci. 2002;110:121-4.

7. Dunsche A, Açil Y, Siebert R, Harder J, Schröder JM, Jepsen S. Expression profile of human defensins and antimicrobial proteins in oral tissues. J Oral Patho Med. 2001;30:154-8.

8. Krisanaprakornkit S, Kimball JR, Weinberg A, Darveau RP, Bainbridge BW, Dale BA. Inducible Expression of Human $\beta$-Defensin 2 byFusobacterium nucleatum in Oral Epithelial Cells: Multiple Signaling Pathways and Role of Commensal Bacteria in Innate Immunity and the Epithelial Barrier. Infect Immun. 2000;68:2907-15.

9. Schröder J-M. Epithelial peptide antibiotics. Biochem Pharmacol. 1999;57:121-34.

10. Khurshid Z, Naseem M, Sheikh Z, Najeeb S, Shahab S, Zafar MS. Oral antimicrobial peptides: Types and role in the oral cavity. Saudi Pharm J. 2016;24:515-24.

11. Ji S, Shin JE, Kim YS, Oh JE, Min BM, Choi Y. Toll-Like Receptor 2 and NALP2 Mediate Induction of Human Beta-Defensins by Fusobacterium nucleatum in Gingival Epithelial Cells. Infect Immun. 2009;77:1044-52.

12. Hertz CJ, Wu Q, Porter EM, Zhang YJ, Weismüller KH, Godowski PJ, et al. Activation of Toll-Like Receptor 2 on Human Tracheobronchial Epithelial Cells Induces the Antimicrobial Peptide Human $\beta$ Defensin-2. J Immunol. 2003;171:6820-6.

13. Goris MGA, Wagenaar JFP, Hartskeerl RA, van Gorp ECM, Schuller S, Monahan AM, et al. Potent Innate Immune Response to Pathogenic Leptospira in Human Whole Blood. PLoS One. 2011;6:e18279.

14. Lo YY, Hsu SH, Ko YC, Hung CC, Chang MY, Hsu HH, et al. Essential Calcium-binding Cluster of Leptospira LipL32 Protein for Inflammatory Responses through the Toll-like Receptor 2 Pathway. J Biol Chem. 2013; 288:12335-44.

15. Werts C, Tapping RI, Mathison JC, Chuang TH, Kravchenko V, Saint Girons I, et al. Leptospiral lipopolysaccharide activates cells through a TLR2-dependent mechanism. Nat Immunol. 2001;2:346-52.

16. Sambri V, Marangoni A, Giacani L, Gennaro R, Murgia R, Cevenini R, et al. Comparative in vitro activity of five cathelicidin-derived synthetic peptides against Leptospira, Borrelia and Treponema pallidum. J Antimicrob Chemother. 2002;50:895-902.

17. Nahori M-A, Fournié-Amazouz E, Que-Gewirth NS, Balloy V, Chignard M, Raetz CRH, et al. Differential TLR Recognition of Leptospiral Lipid A and Lipopolysaccharide in Murine and Human Cells. J Immunol. 2005; 175:6022-31.

18. Joly S, Maze C, McCray PB, Guthmiller JM. Human $\beta$-Defensins 2 and 3 Demonstrate Strain-Selective Activity against Oral Microorganisms. J Clin Microbiol. 2004;42:1024-9.

19. Kimball JR, Nittayananta W, Klausner M, Chung WO, Dale BA. Antimicrobial barrier of an in vitro oral epithelial model. Arch Oral Biol. 2006;51:775-83.

20. Lindow JC, Wunder EA Jr, Popper SJ, Min JN, Mannam P, Srivastava A, et al. Cathelicidin Insufficiency in Patients with Fatal Leptospirosis. PLoS Pathog. 2016;12:e1005943. 